\title{
Effects of forest fragmentation on the spatial genetic structure of Acer saccharum Marsh. (sugar maple) populations
}

\author{
A. G. YOUNG* \& H. G. MERRIAM \\ Ottawa-Carleton Institute of Biology, Department of Biology, Carleton University, Ottawa, Ontario, Canada
}

\begin{abstract}
To examine the effects of forest fragmentation on within-population genetic structure of Acer saccharum, the spatial distributions of allozyme variation in the first-year seedling cohorts of four forest patch populations (patches) were compared with those of four populations within continuous forest (controls). Forest patch populations exhibited less spatial mixing of genotypes than controls at the smallest scale examined $(10-14.1 \mathrm{~m})$, possibly as a result of reduced overlap of seed shadows in patches, which generally had lower densities of reproductive trees. Patch populations exhibited greater mixing of genotypes than controls at the largest scale examined (113.1-141.4 m), possibly as a result of the incorporation of immigrant pollen pools into mating events at forest patch edges. This may extend the spatial range of patch population breeding associations which might otherwise be truncated owing to limited forest patch area. Overall, results suggest that mating events are probably the primary determinant of spatial genetic structure within these cohorts in both forest patch and control populations of $A$. saccharum and that forest fragmentation has affected genetic structure by changing patterns of gene flow within, and possibly among, forest patch populations.
\end{abstract}

Keywords: Acer saccharum, allozyme, forest fragmentation, genetic structure, spatial autocorrelation.

\section{Introduction}

Allozyme based studies of genetic variation have shown that generally tree species exhibit high levels of intrapopulation genetic variation (Muona, 1990). Recent investigations of the distribution of this variation among individuals have indicated that populations may not be random assemblages of genotypes but that genetically similar individuals may be spatially associated (e.g. Perry \& Knowles, 1991; Xie \& Knowles, 1991). Such spatial genetic structure can result from several processes. Restriction of gene flow, owing to limited pollen and/or seed dispersal, may produce isolation by distance and subsequent differentiation among groups of individuals by genetic drift. In this case, spatial genetic structure reflects groups of individuals that commonly interbreed (breeding associations) within populations. Selection may also affect the way genotypes are distributed within popula-

*Correspondence: CSIRO, Division of Plant Industry, GPO Box 1600, Canberra ACT 2601, Australia. tions. Patterns of differentiation among individuals are then the result of the spatial patterns of selection regimes. It is also possible that interactions between life-history traits and environmental factors that exhibit spatial and/or temporal dynamics, e.g. reproductive strategy and disturbance regime, can produce nonrandom association of genotypes, as has been suggested recently by Perry \& Knowles (1991).

Two recent studies of tree populations have shown that populations of the same species can have very different spatial genetic structures, depending on their ecological history and population characteristics. Knowles et al. (1992) observed clumping of allozyme phenotypes in a stand of Larix laricina (Du Roi) K. Koch (tamarack) which had regenerated immediately after clear cutting but not in one that was the result of colonization of an old farm field from an adjacent stand. This was attributed to differences in founding seed source, with the clear cut stand having an in situ seed source, possibly reflecting previous genetic structure, whereas the old field population relied on seed from off-site sources, with consequently more mixing. Similarly, Boyle et al. (1990) found spatial genetic 
structure in a lowland stand of Picea mariana (Mill.) B.S.P. (black spruce) but not in a more dense upland stand. They suggested that this was due to differences in the regeneration dynamics of the two stands with the lowland stand having regenerated without major disturbance and the upland stand being the result of regeneration after fire.

Forest fragmentation, the breaking up of large tracts of continuous forest into small forest patches, can result in severe modification of the forest environment and forest tree populations. Fragmentation has been shown to affect forest microclimate (Young, 1988; Kapos, 1989) and the age structure and density of tree populations (Ranney et al., 1981). It has also been suggested that fragmentation affects disturbance regimes (Saunders et al., 1991) and leads to reduced population sizes (Wilcove, 1987). The objective of this study was to investigate the effects of forest fragmentation on the spatial genetic structure of Acer saccharum Marsh. (sugar maple) populations. Of specific interest was whether forest patches encompass the spatial and population scales required for maintenance of 'normal' breeding associations that occur in continuous forest.

\section{Methods}

\section{Study species}

Acer saccharum (Aceraceae) is a shade tolerant tree (Logan, 1965; Forcier, 1973) capable of sustained population regeneration (Nigh et al., 1985) which generally lives 200-300 years (Ledig \& Korbobo, 1983). It is monoecious and self-compatible, although seed set from selfed flowers is poor (Gabriel, 1967) and selfing is restricted by incomplete dichogamy (Gabriel, 1968). Acer saccharum is both wind and insect pollinated (Gabriel \& Garrett, 1984). Seeds are winged samaras which are wind dispersed.

\section{Experimental design and study populations}

To determine the effects of forest fragmentation, the spatial genetic structures of $A$. saccharum populations in four fragmented forest patches $(a, b, c, d)$ were compared with those of four control populations $(\mathrm{A}, \mathrm{B}, \mathrm{C}$, D) within relatively continuous $A$. saccharumdominated forest. This approach assumes that the present genetic structures of continuous forest populations represent the prefragmentation structures of forest patch populations. Control populations (controls) were population samples located in extensive $A$. saccharum-dominated forest in Gatineau Park, Québec, Canada: $45^{\circ} 35.0^{\prime} \mathrm{N}, 75^{\circ} 55.4^{\prime} \mathrm{W}$. Forest patch populations (patches) were located around North Gower and Manotick, south of Ottawa, in eastern Ontario: $45^{\circ} 10.4^{\prime} \mathrm{N}, 75^{\circ} 40.6^{\prime} \mathrm{W}, 50 \mathrm{~km}$ south of the control populations. These populations were reduced from more continuous forest $100-200$ years ago when the forest in this region was cleared for farming (Middleton, 1982). Forest patches ranged in size from 1.6 ha to 6.3 ha (Table 1). All patches showed signs of human modification. This is probably the result of cutting of trees for wood. The mean densities of reproductive trees (those exhibiting flowers, seed or more than $20 \mathrm{~cm}$ diameter at $1 \mathrm{~m}$ in height) for patch populations 'a', 'b' and ' $c$ ' were approximately one-third lower than for the controls $(P<0.05)$ (Table 1$)$, while patch 'd' had a higher density of reproductive trees than the control populations $(P<0.05)$.

\section{Genetic data}

Within each population, 121 first-year seedlings were sampled from a 1 ha square quadrat using a regular $11 \times 11$ sampling grid with $10 \mathrm{~m}$ intervals between nearest sampling points. All seedlings were removed intact, transplanted into pots and maintained in a greenhouse for the duration of the study.

Following the procedures described in Young et al. (1993), horizontal starch gel electrophoresis was used to obtain allozyme genotypes for all seedlings from mature leaf tissue samples, for 10 putative polymor-

Table 1 Area and density of reproductive trees $\nmid$ for control and patch populations of $A$. saccharum

\begin{tabular}{lll}
\hline & $\begin{array}{l}\text { Area } \\
\text { (ha) }\end{array}$ & $\begin{array}{l}\text { Mean number } \\
\text { (standard error) } \\
\text { of reproductive } \\
\text { trees per } 400 \mathrm{~m}^{2}\end{array}$ \\
\hline Control population & \\
A & - & $7.4(0.9)$ \\
B & - & $6.9(1.0)$ \\
C & - & $7.5(1.3)$ \\
D & - & $7.1(0.9)$ \\
Patch population & & \\
a & 6.3 & $4.1(0.7)$ \\
b & 1.8 & $3.0(1.2)$ \\
c & 1.6 & $5.9(1.2)$ \\
d & 2.0 & $8.3(1.3)$ \\
\hline
\end{tabular}

$\dagger$ Defined as those individuals exhibiting flowers or seed or more than $20 \mathrm{~cm}$ diameter at $1 \mathrm{~m}$ in height. Data from Young et al. 1993. Mean reproductive tree densities for patch populations 'a', 'b' and 'c' are lower $(P<0.05)$ than for controls. Mean reproductive tree density for patch 'd' is higher $(P<0.05)$ than for controls. 
phic allozyme loci for seven enzymes. These were: alcohol dehydrogenase (ADH) E.C. 1.1.1.1 (1 locus), aspartate aminotransferase (AAT) E.C. 2.6.1.1 (1 locus), glucose-6-phosphate isomerase (GPI) E.C. 5.3.1.9 (1 locus), glyceraldehyde-3-phosphate dehydrogenase (GAPDH) E.C. 1.2.1.12 (1 locus), malate dehydrogenase (MDHP) E.C. 1.1.1.37. (NADP) (1 locus), phosphoglucomutase (PGM) E.C. 5.4.2.2 (4 loci), triose-phosphate isomerase (TPI) E.C. 5.3.1.1 (1 locus). Different loci for a single enzyme were numbered in decreasing order of anodal mobility. Alleles at a locus were identified by their mobility relative to the migration of a bromophenol blue marker $\left(R_{\mathrm{f}}\right)$. Phosphoglucomutase exhibited four loci rather than the more usual two (Weeden \& Wendel, 1989). Alleles Pgm-1: $0.375,0.320$ and Pgm-4: 0.205 were excluded from data analysis because they overlapped alleles from $P g m-2$ and $P g m-3$, respectively, and heterozygotes could not be reliably identified based on band intensity. Mendelian inheritance of Aat-2 and Gpi-2 has been verified for $A$. saccharum by Lelliot (1987) and was assumed for the other loci based on concordance between observed and expected banding patterns of putative heterozygotes, given previously suggested enzyme subunit structures (Weeden \& Wendel, 1989; Kephart, 1990).

\section{Spatial analyses}

Spatial autocorrelation (Cliff \& Ord, 1981) and nearest neighbour analyses (Clark \& Evans, 1954) were used to investigate the spatial distribution of allozyme genotypes among individuals within the eight populations. Given the spatial sampling strategy, only genetic structure at scales more than $10 \mathrm{~m}$ could be detected. For each population, only alleles that occurred in at least three individuals and which could occur in less than $n-2$ individuals ( $n=$ sample size) were included in the spatial analyses. This gave between 15 and 21 useful alleles per population.

For spatial autocorrelation, allelic data were coded so that each allele was a variable existing in an individual in one of three states: 1=homozygote, $0.5=$ heterozygote, $0=$ absent. If only two alleles were present at a locus only information from a single locus was used. Moran's I spatial autocorrelation coefficient was calculated following Cliff \& Ord (1981) for each allelic variable, for nine classes of separation distance between individuals: $10-14.1 \mathrm{~m}, \quad 14.2-28.3 \mathrm{~m}$, 28.4-42.4 m, 42.5-56.6 m, 56.7-70.7 m, 70.8-84.9 m, 85-99 m, 99.1-113.2 m, 113.3-141.4 $\mathrm{m}$, using the FORTRAN program SAAP (Wartenberg, 1989). Moran's $I$ was tested for significance under the randomization assumption as a standard normal deviate (Cliff \& Ord,
1981) using Bonferroni criteria (Weir, 1990) for the multiple tests for each distance class provided by the allelic variables. Values of $I$ greater than the expected value of $E(I)=-(n-1)^{-1}$ indicate that genotypes at a given distance are more similar than expected by chance whereas values of $I$ lower than $\mathrm{E}(I)$ indicate less similarity than expected. Initially, for two populations, control ' $\mathrm{B}$ ' and patch ' $\mathrm{a}$ ', alleles in five different frequency classes: less than $0.1,0.1-0.249,0.25-0.749$, $0.75-0.899$, more than 0.9 , were analysed separately. All frequency classes, with the exception of the $0.25-0.749$ class, which contained few (2-4) alleles in any of the populations, were found to be equally informative. This supports the observations of Sokal \& Jacquez (1991) that spatial autocorrelation is independent of gene frequency. Therefore, subsequent analyses for the eight populations combined alleles of all frequencies.

For all alleles with frequencies of less than 0.1, nearest neighbour analysis was conducted following Clark \& Evans (1954) and using Donnelly's (1978) corrections for finite populations. Boyle et al. (1990) have demonstrated that nearest neighbour analysis is more sensitive to localized clustering of such low frequency alleles than spatial autocorrelation using Moran's I. Clark-Evans ratios of mean observed distance to nearest neighbour $\left(r_{\mathrm{A}}\right) /$ expected distance to nearest neighbour $\left(r_{\mathrm{E}}\right)$ of less than 1.0, indicate spatial contagion of genotypes. Ratios of more than 1.0 indicate a regular distribution. Significance was assessed using $r_{\mathrm{A}}$ as a standard normal deviate (Clark \& Evans, 1954; Donnelly, 1978). A neighbour 'match' was considered to be the presence of an allele in either heterozygous or homozygous form.

\section{Results}

Clark-Evans ratios from nearest neighbour analyses, for low frequency (less than 0.1) alleles, for all populations, are presented in Table 2 . None of the distributions of these alleles deviated significantly from random in any of the control or patch populations. However, a large proportion of the observed ratios were more than 1: 23 of 27 ratios for controls and 29 of 38 ratios for patches. This overall weak trend towards regular distributions is probably the result of sampling on a grid.

Spatial autocorrelation results are presented as spatial correlograms of mean Moran's $I$ by individual separation distance class, together with overall significance for each distance class as assessed by Bonferroni criteria. Control population ' $D$ ' showed no deviation from a random distribution of genotypes (Fig. 1a). Control populations ' $A$ ', 'B' and ' $C$ ' also showed no 
Table 2 Clark-Evans ratios $\left(r_{\mathrm{A}} / r_{E}\right)$ for low frequency $(<0.1)$ alleles for control and patch populations of $A$. saccharum

\begin{tabular}{|c|c|c|c|c|c|c|c|c|c|}
\hline \multirow[b]{2}{*}{ Locus } & \multirow{2}{*}{$\begin{array}{l}\text { Allele } \\
\left(R_{\mathrm{f}}\right)\end{array}$} & \multicolumn{4}{|c|}{ Control populations } & \multicolumn{4}{|c|}{ Patch populations } \\
\hline & & A & B & $\mathrm{C}$ & $\mathrm{D}$ & $\mathrm{a}$ & b & c & $\mathrm{d}$ \\
\hline \multirow[t]{3}{*}{ Aat -2} & 0.400 & - & - & - & - & 1.33 & - & - & - \\
\hline & 0.170 & - & - & - & - & 1.15 & - & - & 1.50 \\
\hline & 0.150 & -- & - & 1.03 & - & - & 1.03 & - & - \\
\hline \multirow{5}{*}{ Gpi-2 } & 0.430 & 1.47 & - & 0.89 & - & 1.09 & - & 1.06 & 1.29 \\
\hline & 0.335 & 1.17 & 1.28 & 1.07 & 1.17 & 1.42 & 1.12 & 1.24 & - \\
\hline & 0.325 & - & 1.47 & 1.16 & 1.17 & 1.07 & 1.01 & 1.20 & 1.28 \\
\hline & 0.270 & 0.99 & - & 1.04 & - & - & 1.34 & - & 0.96 \\
\hline & 0.255 & - & 1.35 & - & - & - & 1.39 & - & 1.07 \\
\hline Gapdh-2 & 0.220 & - & - & 1.38 & - & - & - & - & - \\
\hline Mdhp-4 & 0.230 & 1.14 & - & - & 1.28 & - & - & 0.93 & 0.99 \\
\hline$P g m-1$ & 0.390 & - & - & - & - & - & 0.65 & - & - \\
\hline \multirow[t]{3}{*}{ Pgm-2 } & 0.410 & 1.04 & - & 1.24 & 0.90 & 1.26 & 1.21 & 1.12 & 1.03 \\
\hline & 0.325 & - & 1.57 & - & - & 1.16 & 1.14 & 1.03 & - \\
\hline & 0.315 & - & - & - & 1.22 & 1.24 & 1.09 & 1.18 & 1.50 \\
\hline$P g m-3$ & 0.170 & - & - & - & 1.62 & - & - & - & - \\
\hline \multirow[t]{2}{*}{ Pgm-4 } & 0.140 & 1.05 & 0.95 & 1.66 & - & - & - & 0.84 & 1.11 \\
\hline & 0.135 & - & - & - & - & 0.85 & - & - & - \\
\hline$T p i-1$ & 0.470 & - & - & 1.01 & 1.07 & 0.83 & - & 0.65 & 0.90 \\
\hline
\end{tabular}

spatial genetic associations at distances of less than $28.3 \mathrm{~m}$ (Fig. 1a). Beyond this, all three populations exhibited non-random associations of genotypes at various distances. However, there were no obvious trends in genetic similarity across distance classes, either in mean Moran's $I$ or type of association, i.e. positive or negative, and there was little consistency in genetic associations for distance classes among populations. Mean Moran's $I$ values for control population ' $\mathrm{B}$ ', for distance classes 42.5-56.6 m, 70.8-84.9 $\mathrm{m}$ and 113.3-141.4 m, did not match the overall significance for these distances. In each case this was because significance was conferred by the spatial distribution of a single allele: Gpi-2: 0.325, Gapdh-2: 0.275 and Pgm-2: 0.325 , respectively (Fig. 2 ).

Between $14.2 \mathrm{~m}$ and $113.2 \mathrm{~m}$, spatial autocorrelation results for patches were similar to those for controls, with populations exhibiting non-random genetic associations at various spatial scales but no trends in genetic similarity with distance and little consistency among populations (Fig. 1b). At the shortest distance class $(10-14.1 \mathrm{~m})$, three of the four populations $(\mathrm{a}, \mathrm{b}, \mathrm{c})$ had mean Moran's $I$ values of more than $\mathrm{E}(I)$ and two of these populations, 'b' and 'c', showed significant positive association of genotypes. Similarly, at the longest distance class (113.3-141.4 m), all populations had mean Moran's $I$ values of less than E(I), with populations ' $b$ ' and ' $c$ ' showing significant negative associations of genotypes. These results at the shortest and longest distances sampled, and their general consistency across the patch populations, contrast with results from controls.

\section{Discussion}

Although nearest neighbour analyses show no localized spatial clumping of genotypes involving low frequency alleles, spatial autocorrelation indicates that both controls and patches, with the apparent exception of control population ' $D$ ', did exhibit spatial genetic structure. Furthermore, comparison of Moran's $I$ for the shortest and longest individual separation distance classes suggests that patterns of genetic similarity among individuals show some differences between patch and control populations. If control populations are good representations of the genetic structure of patches prior to forest fragmentation, then fragmentation has affected the genetic structure of patch populations.

For control populations 'A', 'B' and 'C', spatial autocorrelation results indicate that genotypes were not distributed randomly within populations. However, Moran's I did not decline with increasing distance between individuals as suggested by Barbujani (1987), for neutral loci under isolation by distance. These results contrast with those of Perry \& Knowles (1991) from three naturally regenerated $A$. saccharum stands, for similar spatial scales and sample sizes, using 
Fig. 1 Spatial correlograms of mean Moran's $I$ by individual separation distance class for $A$. saccharum control and patch populations. $\mathrm{E}(I)=$ expected Moran's $I$. Boxes give overall significance $(P<0.05)$ of genetic association at each distance class: $(+)$ positive association, $(-)$ negative association, (-) no deviation from random. (a) Control populations: A $(\bullet), \mathrm{B}(\square), \mathrm{C}$ (-), D (O). Number of alleles used in analyses: A: 15, B: 16, C: 17, D: 15.(b) Patch populations: a $(\bullet), \mathrm{b}(\square), \mathrm{c}(\bullet), \mathrm{d}$ (0). Number of alleles used in analyses: a: 21, b: 17, c: 17, d: 19 .

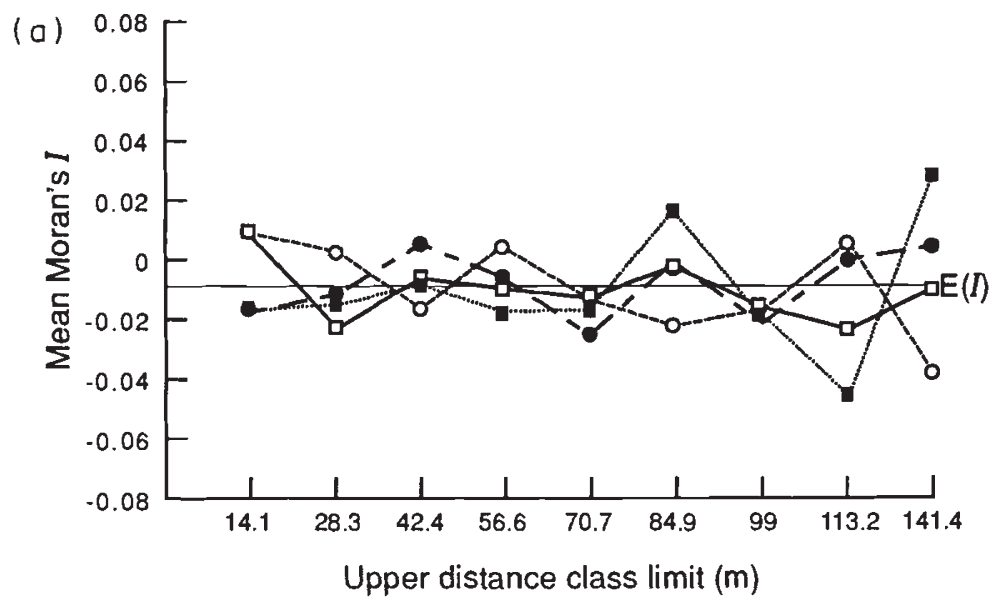

\begin{tabular}{llllllllll|}
\hline $\mathrm{A}$ & $\cdot$ & $\cdot$ & $\cdot$ & $\cdot$ & - & $\cdot$ & $\cdot$ & + & $\cdot$ \\
$\mathrm{B}$ & $\cdot$ & $\cdot$ & + & + & $\cdot$ & - & $\cdot$ & $\cdot$ & + \\
$\mathrm{C}$ & $\cdot$ & $\cdot$ & $\cdot$ & $\cdot$ & $\cdot$ & + & $\cdot$ & - & + \\
$\mathrm{D}$ & $\cdot$ & $\cdot$ & $\cdot$ & $\cdot$ & $\cdot$ & $\cdot$ & $\cdot$ & $\cdot$ & $\cdot$ \\
\hline
\end{tabular}

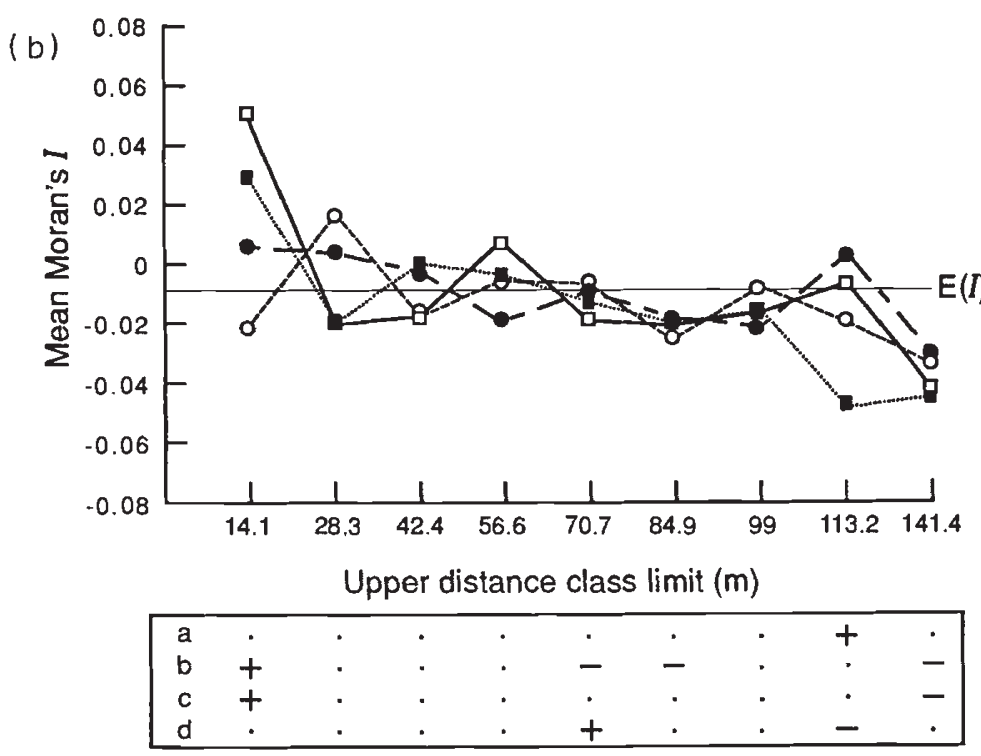

approximately the same number of alleles. Perry \& Knowles (1991) observed clumping of similar allozyme phenotypes up to distances of $20-30 \mathrm{~m}$ in all stands and suggested that this may have been the result of limited pollen and/or seed dispersal.

This does not mean that the spatial genetic structures in control populations are not the products of patterns of mating. Acer saccharum is heterodichogamous, with trees being either protogynous or protandrous. Within a population, blooming of flowers may be spread over up to ten days (Gabriel, 1968). However, the duration of blooming for individual trees can be as short as 2 days for both male and female flowers (Gabriel, 1968). Therefore, patterns of mating may be primarily determined by the spatial distribution of flowering times among trees and the genetic structures observed in controls, with positive and negative associations at various distances, could result from correlations among half-sib progeny of parental trees with complementary flowering periods that are spread throughout the populations. Differences in the distribution of trees with complementary flowering periods would then account for observed among-population differences in patterns of genetic similarity with distance. Murawski \& Hamrick (1991) have described a similar scenario for several tropical angiosperm trees in which they suggest that the timing of flowering of individual trees is important in determining mating relationships. If this is the case, the positive Moran's I values over the longest distance class for control popu- 


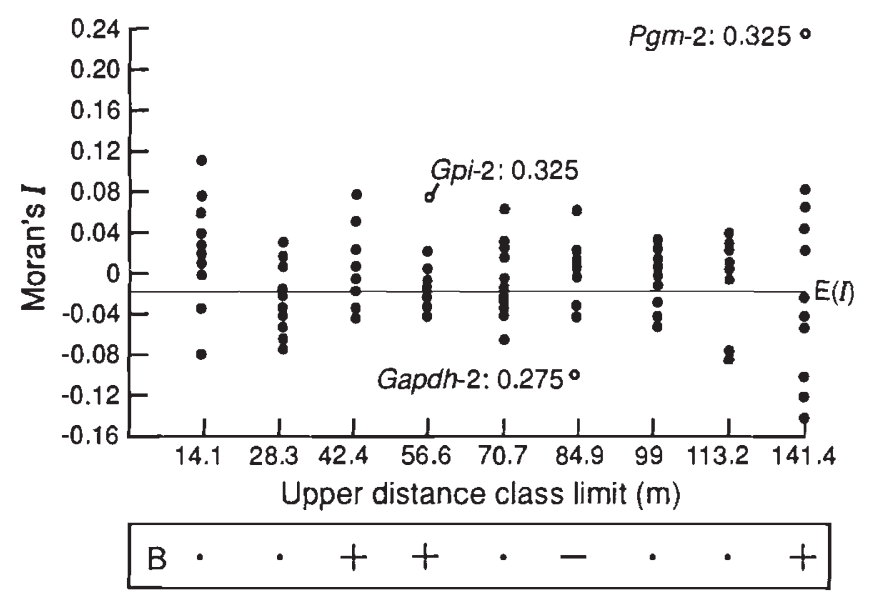

Fig. 2 Moran's $I(\bullet)$ by individual separation distance class for the 16 alleles analysed for $A$. saccharum control population 'B'. Box gives overall significance $(P<0.05)$ of genetic association at each distance class: $(+)$ positive association, $(-)$ negative association, ( $\square$ ) no deviation from random. (O) Moran's I for alleles that confer overall significance.

lations ' $\mathrm{B}$ ' and ' $\mathrm{C}$ ' indicate that pollen movement is extensive, with breeding associations extending over the whole area sampled and possibly beyond, although not encompassing all individuals within the area because of differences in flowering period. Presumably, if flowering time is genetically controlled, which Gabriel (1968) suggests it is, based on year to year consistency in the blooming habit of trees, then such breeding associations may be temporally stable. This may explain the positive inbreeding coefficients observed previously for several populations of $A$. saccharum (Young et al., 1993), which may be the result of a Wahlund effect owing to sampling several spatially coincident but phenologically isolated breeding associations.

Selection can also influence the distribution of genotypes within populations and Perry \& Knowles (1991) also proposed microgeographic selection as a possible mechanism generating spatial genetic structure in the $A$. saccharum stands that they studied. Sokal \& Wartenberg (1983) and Epperson (1990) have suggested that as selection does not affect all loci equally, it may be detected by differences between spatial patterns of alleles at loci subject to selection and neutral loci. Although, as shown in Fig. 2 for control population 'B', alleles often had different Moran's I values for the same distance classes, no consistently different patterns of Moran's $I$ with distance were observed for alleles at any locus in any of the populations. One possible reason for a limited effect of selection is that the population cohort examined was first-year seedlings, which had undergone only a subset of lifetime selective events. Although Foré et al.(1992) have found allozyme allele frequency differences between embryo and seedling cohorts in A. saccharum, which may reflect selection at germination, most selection probably occurs later, during the major mortality period of the first 15 years (Forcier, 1973). Furthermore, if selection were generating genetic structure, it would require a very complex spatial distribution of the environmental variables responsible to produce the observed genetic patterns and environmental patch sizes would have to be small (less than $10 \mathrm{~m}$ diameter).

The similarity of spatial autocorrelation results for patch and control populations between $14.2 \mathrm{~m}$ and $113.2 \mathrm{~m}$ suggests that over a large range of the scales examined the same processes were generating genetic structure. The different patterns of genetic associations among individuals at the shortest and longest distances in patches presumably reflect changes in either population or environment, resulting from forest fragmentation, that have affected these processes. The apparent genetic similarity of individuals separated by distances of less than $14.2 \mathrm{~m}$ in patches ' $a$ ', ' $b$ ' and ' $c$ ' may be due to lower densities of reproductive trees in these populations. Patch population 'd', which had a reproductive tree density higher than the controls, did not exhibit this trend. Johnson (1988) has shown that in open field conditions $A$. saccharum seed dispersal is reduced by an order of magnitude by $30 \mathrm{~m}$ from the seed source and Guries \& Nordheim (1984) suggest that dispersal within forest may be further reduced as samaras are knocked out of autogyration by impaction on trees. Therefore, within-population seed dispersal is probably quite limited, which should lead to clumping of related individuals. This was not observed in control populations, possibly because the density of reproductive trees resulted in significant overlapping of seed shadows, with consequent mixing of progeny of different maternal origins (Fig. 3a). In patch populations, with their lower densities of reproductive trees, overlap of seed shadows may not be as great (Fig. 3b). Therefore, half-sib progeny may form distinct and identifiable patches around maternal trees that are large enough to be detected by the shortest individual comparisons made, i.e. more than $10 \mathrm{~m}$ diameter.

The negative Moran's $I$ values between $113.3 \mathrm{~m}$ and $141.4 \mathrm{~m}$ in patch populations probably relate to limited forest patch area. Three of the four patch populations $(b, c, d)$ were only slightly larger than the 1 ha sampling area, therefore comparisons of individuals in patches at this scale were comparisons among individuals at opposite edges of a forest patch. This may generate the observed negative genetic associations in two ways. Firstly, mating events at these edges may be incorporating immigrant pollen, probably from 
(a)

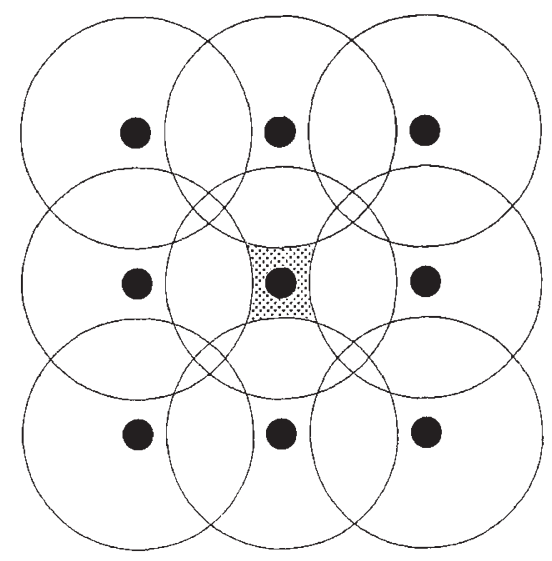

(b)

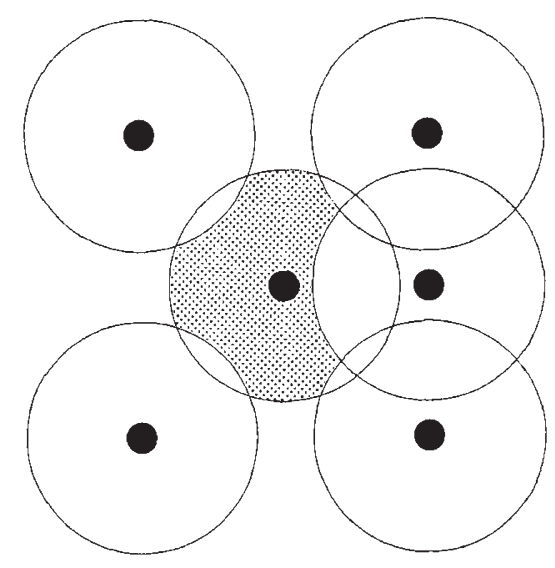

\section{Reproductive tree}

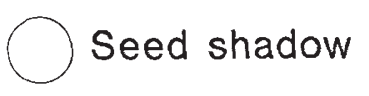

Fig. 3 Hypothetical seed shadows around reproductive $A$. saccharum trees. Shaded area denotes patch of half-sib progeny. (a) Control population. (b) Patch population with density of reproductive trees one-third lower than control.

other forest patch populations. Young et al. (1993) have shown that wind dispersal of pollen is a possible gene flow vector over commonly encountered interpatch distances of several hundred metres. If different forest edges receive pollen from different sources, depending on the spatial arrangement of surrounding forest patches, prevailing wind patterns and pollinator movements, genetic associations among edge individuals will reflect any differences in allele frequencies among these immigrant pollen pools. Secondly, Wales (1967) has shown that the microclimate of forest edges may be different, depending on aspect. If flowering time were at all affected by microclimate, then negative associations among individuals at different forest edges may be because of differences in flowering times of edge trees, which prevent inter-edge mating events.

Overall these results suggest that mating may be an important process in generating spatial genetic structure in A. saccharum populations. Patterns of mating among individuals are probably determined to some extent by individual flowering time and, in large continuous populations, are apparently not limited by pollen dispersal over the scales examined (less than $141.4 \mathrm{~m}$ ). It would appear that forest fragmentation has impacted on the genetic structure of the seedling cohort of forest patch populations, possibly by affecting patterns of gene flow and mating. Patch populations of 1-2 ha may no longer be large enough to encompass the spatial scales of mating events occurring in breeding associations within continuous forest populations. However, matings occurring at patch edges may be incorporating immigrant pollen, possibly generating mating relationships among individuals at greater scales than generally observed in continuous populations, which are reflected in seedling genotypes. This may in effect be extending the range of patch breeding associations which might otherwise be truncated owing to limited forest patch area. In contrast, the spatial mixing of genotypes at short range (less than $14.1 \mathrm{~m}$ ) in patches has been reduced, possibly owing to increased isolation of seed shadows around reproductive trees, which occur at reduced densities in forest patches. Although there was no evidence of the action of selection in generating genetic structure in the seedling cohorts examined, a role for selection in later life-history cannot be discounted based on these data. This may account for the observed differences between the results of this study and those obtained by Perry \& Knowles (1991). More generally, the results of this study indicate the need for more realistic models of mating relationships and gene flow for forest trees if these are to be successfully incorporated into an understanding of within-population genetic structure. The spatial patterns of genetic variation described here are not simple functions of individual separation distance. Certainly, the addition of a temporal component to the spatial elements generally considered should prove instructive.

\section{Acknowledgements}

This research was supported by Carleton University, Agriculture Canada, Environment Canada Parks Service (contract to A.G.Y. and S.I. Warwick) and the Natural Sciences and Engineering Research Council of Canada (operating grant to H.G.M.). Thanks go to the National Capital Commission for allowing collection of seedlings from Gatineau Park and to those landowners who allowed collection of seedlings from their woodlots. Dave Omond assisted with collection and maintenance of seedlings. 


\section{References}

BARBUjANI, G. 1987. Autocorrelation of gene frequencies under isolation by distance. Genetics, 117, 777-782.

BOYLE, T., LIENGSIRI, C. AND PIEWLUANG, C. 1990. Genetic structure of black spruce on two contrasting sites. Heredity, 65, 393-399.

CLARK, P. J. AND EVANS, F. C. 1954. Distance to nearest neighbour as a measure of spatial relationships in populations. Ecology, 35, 445-453.

ClifF, A. D. AND ORD, J. K. 1981. Spatial Processes Models and Applications. Pion, London.

DONNELLY, K. 1978. Simulation to determine the variance and edge-effect of total nearest neighbour distance. In: Hodder, I. R. (ed.), pp. 91-95. Simulation Methods in Archaeology, Cambridge University Press, London.

EPPERSON, B. K. 1990. Spatial autocorrelation of genotypes under directional selection. Genetics, 124, 757-771.

FORCIER, L. K. 1973. Seedling pattern and population dynamics, and the reproductive strategies of sugar maple, beech and yellow birch at Hobbard Brook. Ph.D. Thesis, Yale University.

FORÉ, S. A., HICKEY, R. J., GUTTMAN, S. 1. AND VANKAT, J. L. 1992. Temporal differences in genetic diversity and structure of sugar maple in an old-growth forest. Can. J. Forest Res., 22, 1504-1509.

GABRIEL, W. J. 1967. Reproductive behaviour in sugar maple: self-compatibility, cross-compatibility, agamospermy and agamocarpy. Silvae Genetica, 16, 165-168.

GABRIEL, w. J. 1968. Dichogamy in Acer saccharum. Bot. Gaz., 129, 334-338.

GABRIEL, W. J. AND GARRETT, P. w. 1984. Pollen vectors in sugar maple (Acer saccharum). Can. J. Botany, 62, 2889-2890.

GURIES, R. P. AND NORDHEIM, E. V. 1984. Flight characteristics and dispersal potential of maple samaras. Forest Sci., $\mathbf{3 0}$, 434-440.

JOHNSON, w. C. 1988. Estimating dispersibility of Acer, Fraxinus and Tilia in fragmented landscapes from patterns of seedling establishment. Landscape Ecol., 1, 175-187.

KAPOS, v. 1989. Effects of isolation on the water status of forest patches in the Brazilian Amazon. J. Trop. Ecol., 5, 173-185.

KEPHART, S. R. 1990. Starch gel electrophoresis of plant isozymes: a comparative analysis of techniques. Am. J. Bot., 77, 693-712.

KNOWLES, P., PERRY, D. J. AND FOSTER, H. A. 1992. Spatial genetic structure in two tamarack (Larix laricina (Du Roi) $\mathrm{K}$. Koch) populations with differing establishment histories. Evolution, 46, 572-576.

LEDIG, F. T. AND KORBOвO, D. R. 1983. Adaptation of sugar maple populations along altitudinal gradients: photosynthesis, respiration and specific leaf weight. Am. J. Bot., 70, $256-265$.

LELLIOT, M. 1987. Inheritance of eight enzyme systems in sugar maple (Acer saccharum Marsh.). B.Sc (Hons) Thesis, Lakehead University.

LOGAN, K. T. 1965. Growth of tree seedlings as affected by light intensity: I. White Birch, Yellow Birch, Sugar Maple and
Silver Maple. Canadian Department of Forestry Publication No. 1121.

MIDDLETON, J. D. 1982. On certain spatial characteristics of the distribution of woodland species in farmland. Ph.D Thesis, Carleton University.

MUONA, O. 1990. Population genetics in forest tree improvement. In: Brown, A. H. D., Clegg, M. T., Kahler, A. L. and Weir, B. S. (eds) Plant Population Genetics, Breeding and Genetic Resources, pp. 282-298. Sinauer Associates, Sunderland.

MURAWSKI, D. A. AND HAMRICK, J. L. 1991. The effect of the density of flowering individuals on the mating systems of nine tropical tree species. Heredity, 67, 167-174.

NIGH, T. A., PALlardy, S. G. AND GaRReTT, H. E. 1985. Sugar maple-environment relationships in the River Hills and Central Ozark Mountains of Missouri. Am. Midland Naturalist, 114, 235-251.

PERRY, D. J. AND KNOWLES, P. 1991. Spatial genetic structure within three sugar maple (Acer saccharum Marsh.) stands. Heredity, 66, 137-142.

RANNEY, J. W., BRUNNER, M. C. AND LEVENSON, J. B. 1981. The importance of edge in the structure and dynamics of forest islands. In: Burgess, R. L. and Sharpe, D. M. (eds) pp. 67-96. Forest Island Dynamics in Man-Dominated Landscapes, Springer Verlag, New York.

SAUNDERS, D. A., HOBBS, R. J. AND MARGULES, C. R. 1991. Biological consequences of ecosystem fragmentation: a review. Conserv. Biol., 5, 18-32.

SOKAL, R. R. AND JAQUEZ, G. M. 1991. Testing inferences about microevolutionary processes by means of spatial autocorrelation analysis. Evolution, 45, 152-168.

SOKAL, R. R. AND WARTENBERG, D. E. 1983. A test of spatial autocorrelation analysis using an isolation-by-distance model. Genetics, 105, 219-237.

WALES, B. A. 1967. Climate, microclimate and vegetation relationships on north and south forest boundaries in New Jersey. The William L. Hutcheson Memorial Forest Bulletin, 2, 1-60.

WARTEnberg, D. E. 1989. saAP - A Spatial Autocorrelation Analysis Program. University of Medical and Dentistry of New Jersey, NJ.

WEEDEN, N. F. AND WENDEL, J. F. 1989. Genetics of plant isozymes. In: Soltis, D. E. and Soltis, P. S. (eds) Isozymes in Plant Biology, Dioscorides, Portland, pp. 46-72.

wElR, B. S. 1990. Genetic Data Analysis. Sinauer Associates, Sunderland.

wilcove, D. S. 1987. From fragmentation to extinction. Natural Areas J., 7, 23-29.

XIE, C. Y. AND KNOWLES, P. 1991. Spatial genetic structure within natural populations of jack pine (Pinus banksiana). Can.J. Bot., 69, 547-551.

YounG, A. G. 1988. The ecological significance of the edge effect in a fragmented forest landscape. M.Sc. Thesis, University of Auckland.

YOUNG, A. G., MERRIAM, H. G. AND WARWICK, S. r. 1993. The effect of forest fragmentation on genetic variation in Acer saccharum Marsh. (sugar maple) populations. Heredity, 71, 277-289. 